\title{
Conformational Properties of Tetramethylammonium Gellan Gum in Aqueous Solutions
}

\author{
Etsuyo Ogawa \\ Showagakuin Junior College, Higashisugano 2-17-1, \\ Ichikawa, Chiba 272, Japan
}

(Received October 4, 1994)

\begin{abstract}
Conformational properties of tetramethylammonium type gellan gum in aqueous solutions were studied by osmometry. The measurements were carried out at $28^{\circ}$ and $40^{\circ} \mathrm{C}$ in aqueous solutions of six different tetramethylammonium chloride concentrations $\left(C_{\mathrm{s}}\right.$, ranging from 0.0125 to $0.5 \mathrm{~mol} \mathrm{dm}^{-3}$ ). It was found that the $\bar{M}_{n}$ values obtained at different $C_{\mathrm{S}}$ agreed with each other within the experimental error and the average $\bar{M}_{n}$ value obtained at $28^{\circ} \mathrm{C}\left(\left[\bar{M}_{n}\right]^{(28)}\right)$ was almost twice the value at $40^{\circ} \mathrm{C}\left(\left[\bar{M}_{n}\right]^{(40)}\right)$, which suggests association of two molecules. The ionic strength dependence of $\mathrm{A}_{2}$ at $28^{\circ} \mathrm{C}$ can be quantitatively described by the theory for a charged long rod model, while at $40^{\circ} \mathrm{C} A_{2}$ shows a linear relationship with respect to $1 / C_{\mathrm{s}}{ }^{1 / 2}$.

KEY WORDS Gellan Gum / Osmotic Pressure / Number Average Molecular Weight / Osmotic Second Virial Coefficient / Tetramethylammonium Gellan Gum / Polyelectrolyte / Molecular Conformation / Aqueous Solution /
\end{abstract}

Gellan gum is an extracellular polysaccharide produced by Pseudomonas elodea, consisting of tetrasaccharide repeating sequences with a carboxyl side group ${ }^{1,2}$ (Figure 1), and it forms a thermoreversible gel in aqueous solutions by a conformational transition. ${ }^{4}$ It is considered that the molecular conformation of gellan gum in solutions changes from a disordered state (single coil) to an ordered state (probably a double helix) by lowering temperature, and the subsequent alignment of the ordered regions is responsible for gel formation. The conformational transition temperature of gellan gum in solutions has been reported to be around $32^{\circ} \mathrm{C}$. ${ }^{5}$ Its detailed mechanism, however, has not been clarified yet.

In this work, to obtain fundamental data for the molecular conformation of gellan gum in aqueous solutions, molecular weights and second virial coefficients were measured by osmometry. The measurements were carried out at two different temperatures (28 and $40^{\circ} \mathrm{C}$ ) in the tetramethylammonium chloride
(TMACl) solutions (TMACl concentration $C_{\mathrm{S}}=0.0125-0.5 \mathrm{~mol} \mathrm{~cm}^{-3}$ ) using the tetramethylammonium (TMA) type gellan gum.

To obviate any confusion in the subsequent description, (28) or (40) in superscript will be used hereafter to designate the temperature at which the data were obtained and bracket will designate the average of the data, e.g., $\bar{M}_{n}{ }^{(28)}$ is the number average molecular weight obtained at $28^{\circ} \mathrm{C}$ in each $C_{\mathrm{S}}$ solution and $\left[\bar{M}_{n}\right]^{(28)}$ the average value of $\bar{M}_{n}^{(28)}$.

\section{EXPERIMENTAL}

The sample of gellan gum (sodium type gellan gum; supplied by Kelco Division of

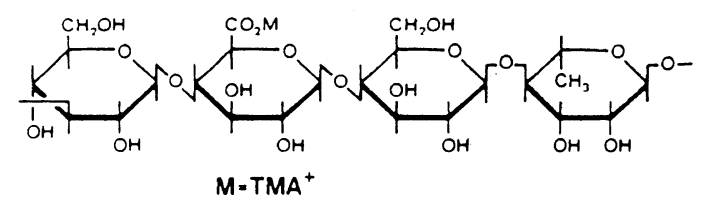

Figure 1. Chemical repeat units of gellan gum. ${ }^{3}$ 
Merck \& Co., Inc.) was converted to TMA-salt by passing through a column of cation exchange resin (Amberlite IR120B) ${ }^{6}$; the bulky counter cations such as TMA cations can inhibit gelation. The conversion to TMA-salts was checked by metal contents of the TMAgellan samples (Table I). The TMA-gellan was dissolved in $\mathrm{TMACl}$ solutions and stirred for $2 \mathrm{~h}$ at $60^{\circ} \mathrm{C}$. The TMA-gellan solutions were dialyzed $3-5$ days at $40^{\circ} \mathrm{C}$ against $\mathrm{TMACl}$ solutions and diluted by this TMACl solutions. Concentrations of the solutions were determined using a Union-Giken Differential Refractometer Model RM-102. A Hewlett-Packard High Speed Membrane Osmometer Model 503 having a special type of glass tube was employed for the measuremnts. To avoid the contamination of the solutions with metallic ions, the stainless steel cell in the original design was replaced by a 6-Nylon cell, and other metallic parts of the instrument such as the solvent reservoir and stoppercocks were re- placed by those made of glass or synthetic resin.

\section{RESULTS AND DISCUSSION}

\section{Number Average Molecular Weights}

Osmotic pressure measurements were carried out at $40^{\circ} \mathrm{C}$ and $28^{\circ} \mathrm{C}$ for six solutions $\left(C_{\mathrm{S}}=\right.$ $\left.0.0125,0.02,0.05,0.075,0.2,0.5 \mathrm{~mol} \mathrm{dm}^{-3}\right)$. The $\pi / c$ vs. $c$ plots are shown in Figures $2 \mathrm{a}$ and $2 b . \pi$ is the osmotic pressure and $c$ the polymer

Table I. Metal contents in the TMA-gellan samples ${ }^{\mathrm{a}}$

\begin{tabular}{lrrrr}
\hline \multicolumn{1}{c}{ Sample } & $\mathrm{Na}$ & $\mathrm{K}$ & $\mathrm{Ca}$ & $\begin{array}{c}\mathrm{Mg} \\
\end{array}$ \\
& & & & $\mu \mathrm{gg}^{-1}$ \\
\hline Na-gellan gum & 33000 & 3320 & 1420 & 110 \\
TMA-gellan gum & 170 & 70 & 8 & 2 \\
\hline
\end{tabular}

${ }^{a}$ Metal contents were measured by flame spectrophotometry $(\mathrm{Na}, \mathrm{K})$ and flame atomic absorption spectrometry (Ca, Mg). (Perkin Elmer Model 3100).
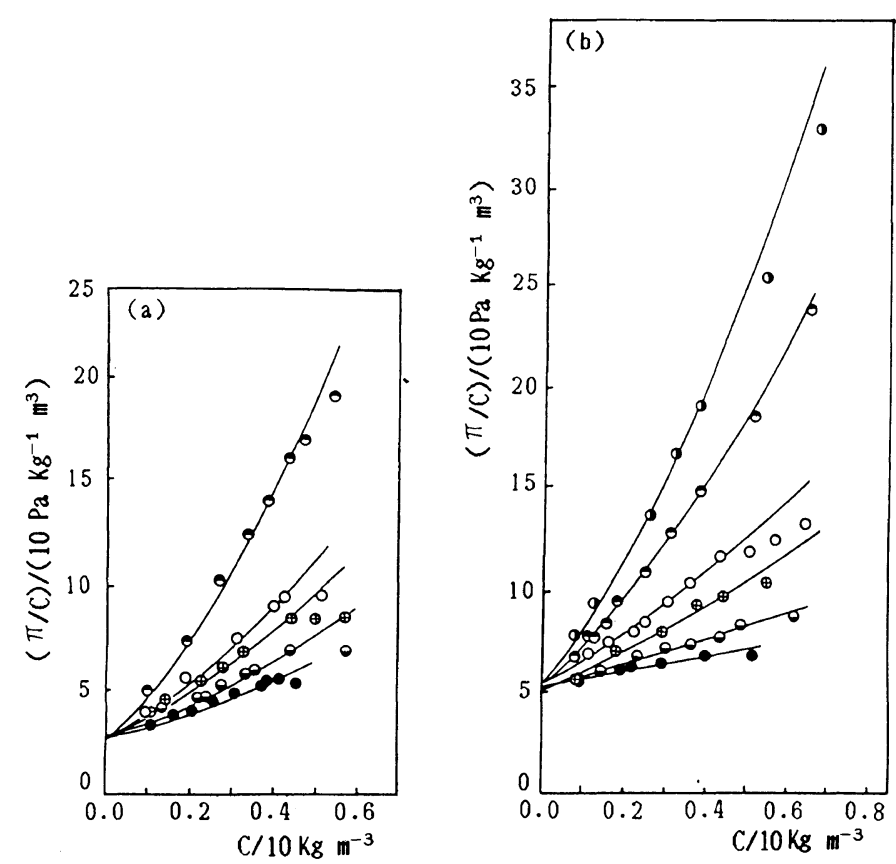

Figure 2. Plots of $\pi / c$ vs. $c$ for the TMA-gellan solutions at $28^{\circ} \mathrm{C}$ (a) and $40^{\circ} \mathrm{C} \mathrm{(b):} \mathrm{TMACl} \mathrm{concentration}$ $\left(\mathrm{mol} \mathrm{dm}^{-3}\right), \odot, 0.0125 ; \ominus, 0.02 ; \bigcirc, 0.05 ; \oplus, 0.075 ; \ominus, 0.2 ; 0,0.5$. The solid lines denote the values calculated from eq 2 using the values of $\bar{M}_{n}$ and $A_{2}$ shown in Table II. 

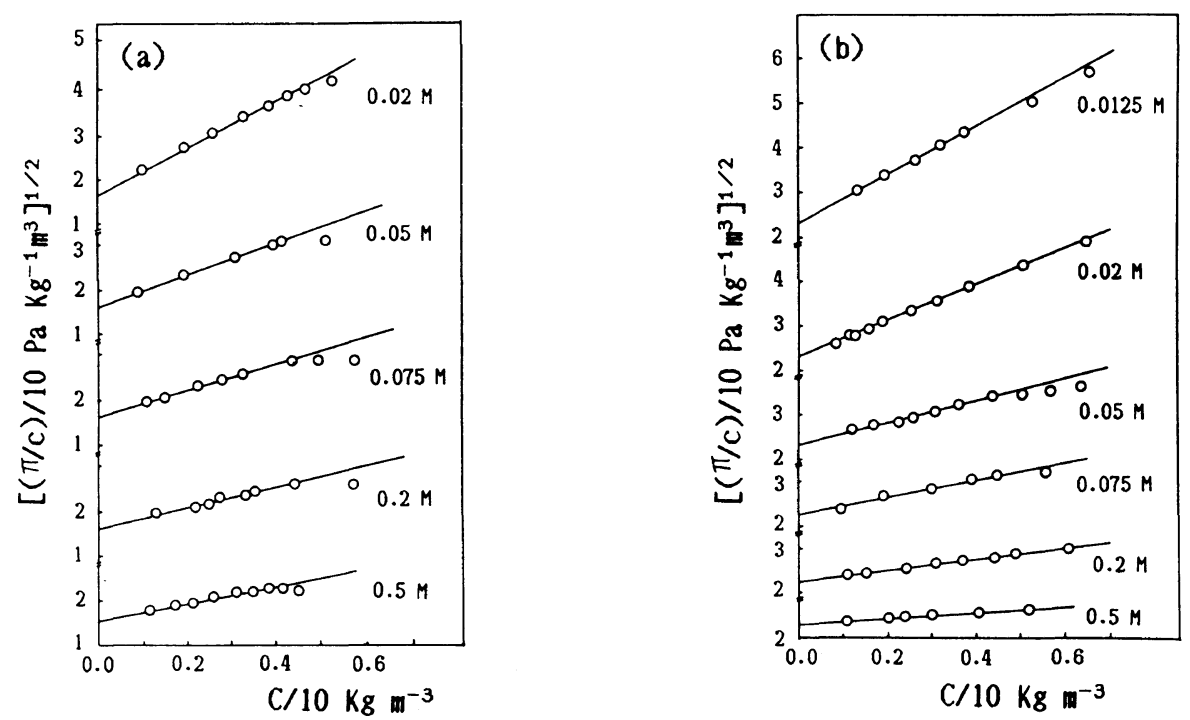

Figure 3. Plots of $(\pi / c)^{1 / 2} v s . c$ for the TMA-gellan solutions at $28^{\circ} \mathrm{C}$ (a) and $40^{\circ} \mathrm{C}(\mathrm{b})$.

concentration. The $\pi / c$ values linearly increased in the low concentration region of the sample but deviated downward above about $c=0.45$ $0.5\left(10 \mathrm{~kg} \mathrm{~m}^{-3}\right)$. The viscosities of the solutions increased at the same concentration region. It is supposed that in the high concentration region of the sample, the gel formation may occur at least partly. During the measurements, however, the solution was stable as a whole without gelation and a good reproducibility of the data was obtained. Therefore, the data in the low concentration region, below about $c=0.45-0.5\left(10 \mathrm{~kg} \mathrm{~m}^{-3}\right)$, were used for the following calculations. It is well known that the osmotic pressure for the polymer solution is expressed by the following equation with appropriate value of $g .^{7}$

$$
\pi / c=\left(R T / \bar{M}_{n}\right)\left[1+A_{2} \bar{M}_{n} c+g\left(A_{2} \bar{M}_{n}\right)^{2} c^{2}\right]
$$

Here $R$ is the gas constant and $T$ the absolute temperature. By assuming $g=1 / 4$, eq 1 is reformed to the following square-root equation.

$$
(\pi / c)^{1 / 2}=\left(R T / \bar{M}_{n}\right)^{1 / 2}\left(1+\bar{M}_{n} A_{2} c / 2\right)
$$

As shown in Figures $3 a$ and $3 b$, the observed values well agree with the equation shown by straight lines in the figure. Thus, number average molecular weights $\bar{M}_{n}$ and osmotic second virial coefficients $A_{2}$ were determined from these plots and listed in Table II. It was found that the $\bar{M}_{n}{ }^{(28)}$ (or $\bar{M}_{n}^{(40)}$ ) values at different $C_{S}$ agreed with each other within the experimental error and the average $\bar{M}_{n}{ }^{(28)}$ value $\left[\bar{M}_{n}\right]^{(28)}$ is almost twice the value $\left[\bar{M}_{n}\right]^{(40)}$ which suggests association of the two molecules at $28^{\circ} \mathrm{C}$.

\section{Second Virial Coefficients}

The slope of each $(\pi / c) v s . c$ plot in Figure 2 gives an $A_{2}$ value containing the contribution from third virial term. The paramter $g$ in eq 1 relates to the third virial coefficient $A_{3}$, $g=A_{3} / A_{2}{ }^{2} M$. To diminish the third virial contribution, $g=1 / 4$ (eq 2) is often used. However, this $g$ value is a rather empirical ${ }^{8}$ and its applicability to polyelectrolyte aqueous solutions is not fully established yet. Then, to evaluate $A_{2}$ and $g$ separately, we adopted the Stockmayer-Casassa plot $^{9}$, i.e., $[(\pi / c R T)-1 /$ $\left.\bar{M}_{n}\right] / c$ vs. $c$, using the $\left[\bar{M}_{n}\right]^{(28)}$ and $\left[\bar{M}_{n}\right]^{(40)}$ values obtained above. The plotted points for 
Table II. Number average molecular weights and second virial coefficients of the TMA-gellan in $\mathrm{TMACl}$ solutions at 28 and $40^{\circ} \mathrm{C}$

\begin{tabular}{|c|c|c|c|c|c|c|c|c|}
\hline \multirow{4}{*}{$\frac{C_{\mathrm{s}}}{\mathrm{mol} \mathrm{dm}^{-3}}$} & \multirow{2}{*}{\multicolumn{2}{|c|}{$\bar{M}_{n} \times 10^{-4 \mathrm{a}}$}} & \multicolumn{4}{|c|}{$A_{2} \times 10^{3} / \mathrm{mol} \mathrm{kg}^{-2} \mathrm{~m}^{-3}$} & \multirow{2}{*}{\multicolumn{2}{|c|}{$g^{\mathrm{b}}$}} \\
\hline & & & \multirow{2}{*}{\multicolumn{2}{|c|}{$28^{\circ} \mathrm{C}$}} & \multirow{2}{*}{\multicolumn{2}{|c|}{$40^{\circ} \mathrm{C}$}} & & \\
\hline & \multirow{2}{*}{$28^{\circ} \mathrm{C}$} & \multirow{2}{*}{$40^{\circ} \mathrm{C}$} & & & & & \multirow[t]{2}{*}{$28^{\circ} \mathrm{C}$} & \multirow[t]{2}{*}{$40^{\circ} \mathrm{C}$} \\
\hline & & & $(\mathrm{R})^{\mathrm{a}}$ & $(\mathrm{SC})^{\mathrm{b}}$ & $(\mathrm{R})^{\mathrm{a}}$ & $(\mathrm{SC})^{\mathbf{b}}$ & & \\
\hline 0.0125 & - & $4.9_{3}$ & - & - & $9.5_{7}$ & 9.6 & & 0.23 \\
\hline 0.0200 & $9.7_{6}$ & $5.0_{2}$ & $7.1_{8}$ & 7.2 & $7.1_{4}$ & 7.0 & 0.25 & 0.27 \\
\hline 0.0500 & $9.8_{7}$ & $4.8_{9}$ & $4.5_{0}$ & 4.6 & $4.4_{0}$ & 4.2 & 0.21 & 0.36 \\
\hline 0.0750 & $9.5_{3}$ & $5.2_{0}$ & $3.9_{1}$ & 3.8 & $3.4_{0}$ & 3.2 & 0.26 & 0.23 \\
\hline 0.2000 & $9.8_{7}$ & $5.2_{0}$ & $3.0_{2}$ & 3.1 & $2.1_{4}$ & 2.2 & 0.24 & 0.25 \\
\hline 0.5000 & $10.0_{6}$ & $4.8 \mathrm{~g}$ & $2.4_{0}$ & 2.3 & $1.2_{5}$ & 1.1 & 0.28 & 0.21 \\
\hline (Average) & $9.8_{3}$ & $5.0_{1}$ & & & & & 0.25 & 0.26 \\
\hline
\end{tabular}

${ }^{a}$ Determined by the squre-root plots (eq 2). ${ }^{b}$ Determined by the Stockmayer-Casassa procedure.

each $C_{\mathrm{s}}$ was fitted by a straight line, and $A_{2}$ and $g$ were determined from the intercept and the slope of the line, respectively. The results are also shown in Table II together with the data from eq 2 . The $A_{2}$ values evaluated from these two plots agree well and the $g$ values obtained by the Stockmayer-Casassa procedure are also close to $1 / 4$ as assumed in the above square-root plots. From these results it is considered that eq 1 , with $g=1 / 4$, holds for the TMA-gellan solutions.

On the assumption that the macroion is a point particle having $-Z$ charge, the second virial coefficients of ideal solutions can be expressed by eq 3 derived from the theory of Donnan and Guggenheim. ${ }^{10,11}$

$$
A_{2}=10^{3} Z^{2} / 4 M^{2} C_{\mathrm{S}}
$$

Here, $Z$ is the charge of each macroion and $C_{\mathrm{s}}$ the concentration of the salt solution. In the derivation of eq 3 , the excluded-volume of the macroions and the electrostatic interactions among ions are tacitly ignored. It was reported that for rigid molecules such as gloubler protein the contribution of the Donnan effect to the second virial coefficient is usually much greater than the excluded volume effect except for low charges or high salt concentrations, so the second virial coefficient should be proportional to $1 / C_{\mathrm{S}}$ as shown in eq $3 .^{12-15}$ For flexible

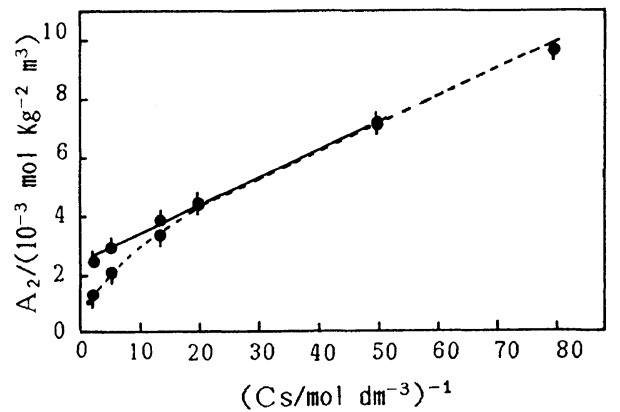

Figure 4. Plots of $A_{2}$ vs. $1 / C_{\mathrm{S}}$ for the TMA-gellan in TMACl solutions at $28^{\circ} \mathrm{C}\left({ }^{\circ}\right)$ and $40^{\circ} \mathrm{C}(\rho)$.

macroions the situation is complicated by the fact that the size of the macroion varies with salt concentration. A further complication arises if ions, the counter ions for instance, bind to the macroion by electrostatic interactions. This may be explained in terms of a reduction of the effective charge on the macroion or as a decerase in the activity coefficient of the both ions. In either case, it results in a diminution of the apparent second virial coefficient.

The $A_{2}$ vs. $1 / C_{\mathrm{S}}$ plots are shown in Figure 4. It is found that above $1 / C_{\mathrm{s}}=c a .20\left(\mathrm{~mol}^{-1} \mathrm{dm}^{3}\right.$, below $C_{\mathrm{S}}=c a .0 .075 \mathrm{~mol} \mathrm{dm}^{-3}$ ) both data of $A_{2}{ }^{(28)}$ and $A_{2}{ }^{(40)}$ coincide and form a straight line, while below $1 / C_{\mathrm{S}}=c a .20\left(\mathrm{~mol}^{-1} \mathrm{dm}^{3}\right)$ the data at $40^{\circ} \mathrm{C}$ deviate downward from this straight line. These results suggest the differ- 
ence between two conformations of TMAgellan at $28^{\circ} \mathrm{C}$ and $40^{\circ} \mathrm{C}$ due to the decrease of electrostatic interactions among macroions with increasing salt concentration. It is found that the second virial coefficients observed are considerably lower than those expected from eq 3 ; the ratio of the observed $A_{2}{ }^{(28)}$ or $A_{2}{ }^{(40)}$ to the calculated one were $0.25,0.3$, 0.45 , and 0.6 at $1 / C_{\mathrm{s}}=80,50,20$, and 13.3 $\left(\mathrm{mol}^{-1} \mathrm{dm}^{3}\right)$, respectively. These observations can often be interpreted in terms of the phenomenon of counterion condensation (ionbinding) by the electrostatic interactions. ${ }^{13}$

\section{Ionic Strength Dependence of the Second Virial Coefficients}

From the McMillan-Mayer theory applied to solutions of rigid macromolecules, $A_{2}$ is given as ${ }^{16}$ :

$$
A_{2}=\frac{1}{2} N_{A} M^{-2} \beta
$$

where $N_{\mathrm{A}}$ is Avogadro's number, and $\beta$ the excluded volume. We consider rigid rod molecules of diameter $d$ and length $L$, with the assumption $L>>d$. By taking only the hardcore interactions into account, the $A_{2}$ in eq 4 becomes $^{16}$

$$
A_{2}=\frac{1}{4} \pi M^{-2} N_{\mathrm{A}} L^{2} d
$$

We next consider a highly charged rodlike macromolecule $(L>>d)$. It is assumed that the total excluded volume is the sum of a hard-core part $\left(\beta_{\mathrm{c}}\right)$ and an electrostatic part $\left(\beta_{\mathrm{e}}\right){ }^{15,17}$

$$
\beta=\beta_{\mathrm{c}}+\beta_{\mathrm{e}}
$$

An exact expression for this electrostatic part of the excluded volume between the two charged rigid rodlike particles of finite thickness is not yet available. As proposed by Brenner and Parsegian, ${ }^{18}$ by replacing each rodlike particle by a line charge having the effective charge density different from the original one and using the solution of the linearized Poisson-Boltzmann equation of the line charge for the potential, we calculated the electrostatic contribution to the excluded volume within the Debye-Hückel approximation as shown in eq $7 .{ }^{17,19,20}$

$$
\beta_{\mathrm{e}}=\left(\frac{\pi}{2}\right) L^{2} \kappa^{-1}\left(\ln Y+\gamma-\frac{1}{2}+\ln 2\right)
$$

with

$$
Y=2 \pi v_{\text {eff }}^{2} Q \kappa^{-1} \exp (-\kappa d)
$$

where $\gamma$ denotes Euler's constant $(=0.5772)$, $v_{\text {eff }}$ the effective charge density, $Q$ the Bjerrum length $\left(0.726 \mathrm{~nm}\right.$ for water at $\left.28^{\circ} \mathrm{C}\right)$, and $\kappa^{-1}$ the Debye length where $\kappa$ is defined by $\kappa^{2}=8 \pi Q n_{\mathrm{S}}\left(8 \pi N_{\mathrm{A}} Q C_{\mathrm{S}} / 1000\right)$ with $n_{\mathrm{S}}$ being the number density of added salt. Equation 7 is accurate within $2 \%$ for $Y>2 .{ }^{20}$ From eq $4-7$, the theoretical expression for $A_{2}$ for the uniformly charged rigid rodlike molecule can be written as follows ${ }^{17}$ :

$$
A_{2}=\left(\pi N_{\mathrm{A}} / 4 M_{\mathrm{L}}^{2}\right)\left[d+\kappa^{-1}(\ln Y+0.7703)\right]
$$

where $M_{\mathrm{L}}(=M / L)$ is the molecular weight per counter length. So far, two fundamental approaches to evaluate the value of $v_{\text {eff }}$ was reported. ${ }^{21}$ In this work, it was evaluated by the following equation derived from the solution of the linearized Poisson-Boltzmann equation along with the Manning's ion condensation hypothesis ${ }^{22}$ (see ref 17 and 23).

$$
v_{\text {eff }}=\left[(Q \kappa d / 2) K_{1}(\kappa d / 2)\right]^{-1}
$$

Here $K_{1}$ denotes the first-order modified Bessel function.

The molecular parameters, such as $M_{\mathrm{L}}$ and $d$, for the TMA-gellan were determined in aqueous $\mathrm{TMACl}$ at $25^{\circ} \mathrm{C}$ from light scattering measurements. ${ }^{5,24}$ The $M_{\mathrm{L}}$ value obtained on the assumption of rigid rodlike helical conformation was equal to $725\left(\mathrm{~nm}^{-1}\right),{ }^{5}$ and the $d$ value estimated by use of the Yamakawa theory ${ }^{25}$ for the wormlike chain ${ }^{24}$ was $2.4(\mathrm{~nm})$. Computation of $A_{2}$ was made from eq 8 and 9 using these $M_{\mathrm{L}}$ and $d$ values. Since L (about $70 \mathrm{~nm}$ ) for the sample in this study is much larger than the Debye length $(2.5 \mathrm{~nm})$ at 


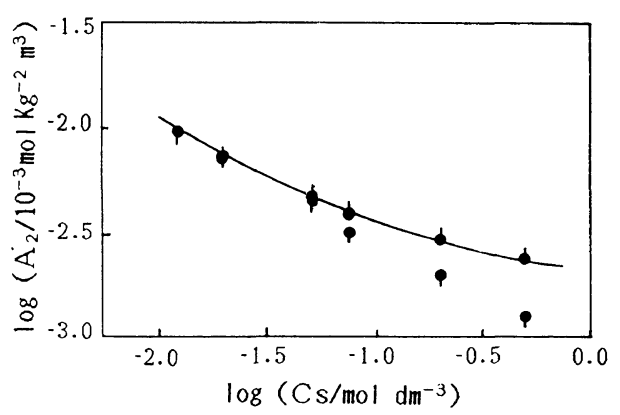

Figure 5. Comparison between the measured and theoretical $A_{2}$ values: data at $28^{\circ} \mathrm{C}(\phi)$ and $40^{\circ} \mathrm{C}(\boldsymbol{Q})$. The solid line denotes the values calculated from eq 7-9 with $M_{\mathrm{L}}=725 \mathrm{~nm}^{-1}$ and $d=2.4 \mathrm{~nm}$.

$C_{\mathrm{S}}=0.0125\left(\mathrm{~mol} \mathrm{dm}^{-3}\right)$, i.e., the lowest $C_{\mathrm{S}}$ studied, the assumpution $(L \gg d)$ is well fulfilled. ${ }^{20}$ The results are compared with the present data in Figure 5. It is found that the calculated $A_{2}$ curve is in good agreement with the experimental data of $A_{2}{ }^{(28)}$ throughout the entire $C_{\mathrm{S}}$ range, while it deviates considerably from the data of $A_{2}{ }^{(40)}$, except for the lowest salt concentration $\left(C_{\mathrm{S}}=0.0125 \mathrm{~mol}\right.$ $\left.\mathrm{dm}^{-3}\right)$. The hard-core $A_{2}$ value of this sample calculated from eq 5 is $2.2 \times 10^{-3}$ $\left(\mathrm{mol} \mathrm{kg}^{-2} \mathrm{~m}^{3}\right)$. The experimental hard-core $A_{2}$ value estimated by extrapolating $A_{2}$ vs. $1 / C_{\mathrm{S}}$ to zero $1 / C_{\mathrm{S}}$ is $c a .2 .4 \times 10^{-3}\left(\mathrm{~mol} \mathrm{~kg} \mathrm{~m}^{-2} \mathrm{~m}^{3}\right)$ at $28^{\circ} \mathrm{C}$, which is in good agreement with the calculated one. Though several approximations have been used in the theoretical calculation of $A_{2}$, (see ref 17 and 26), it may be concluded that the theory for the long charged rod model almost quantitatively describes the ionic strength dependence of $A_{2}{ }^{(28)}$ for the TMAgellan in TMACl solutions. Importantly, this conclusion does not hold for the data of $A_{2}{ }^{(40)}$.

Kawakami and Norisuye, ${ }^{26}$ and Nicolai and Mandel $^{17}$ respectively studied the ionic strength dependences of $A_{2}$ for sodium xanthan and DNA in $\mathrm{NaCl}$ solutions. Kawakami and Norisuye compared the experimental values of $A_{2}$ with the values calculated from eq 8 and 9 over a wide $C_{\mathrm{S}}$ range $\left(C_{\mathrm{S}}=0.005-1.0 \mathrm{~mol}\right.$ $\left.\mathrm{dm}^{-3}\right)$. They found that the experimental data agreed with the calculated one below $C_{\mathrm{S}}=0.2$ $\left(\mathrm{moldm}^{-3}\right)$, but deviated above $C_{\mathrm{S}}=0.2$ $\left(\mathrm{moldm} \mathrm{d}^{-3}\right)$. Moreover, by incoporating the intermolecular attractive interactions, they showed a good agreement between the calculated and observed values throughout the entire $C_{\mathrm{S}}$ range observed. In their work on short DNA $(\sim 50 \mathrm{~nm})$, Nicolai and Mandel incorporated end effects in the calculation of the excluded volume (eq 7), and found that the calculated $A_{2}$ values were in satisfactory agreement with the experimental ones.

The ionic strength dependences of $A_{2}$ for linear polyelectrolytes such as sodium poly(styrenesulfonate) have been studied by several authors. ${ }^{15,27-29}$ It was found experimentally that $A_{2}$ is linearly dependent on $1 / C_{\mathrm{S}}{ }^{1 / 2}$ at higher ionic strengths whereas the lineality between $A_{2}$ and $1 / C_{\mathrm{S}}$ holds only at low ionic strengths. Alexandrowicz presented a theory which accounts for the linear dependence of $A_{2}$ on $1 / C_{\mathrm{S}}{ }^{1 / 2} .^{30}$ It has been considered that the linear polyelectrolytes have more or less coiled conformation at high ionic strengths. As the ionic strength is decreased, the polyelectrolyte coil is expanded due to the electrostatic repulsion, which can be regarded as a kind of excluded volume effect. Consequently the polyelectrolyte chain takes a highly extended form at low ionic strength. Figure 6 shows the plots of $A_{2} v s .1 / C_{\mathrm{S}}{ }^{1 / 2}$. It can be seen that except for the lowest $C_{\mathrm{S}}\left(=0.0125 \mathrm{~mol} \mathrm{dm}^{-3}\right)$, the data points for $A_{2}{ }^{(40)}$ follow a straight line, while those for $\mathrm{A}_{2}{ }^{(28)}$ deviate upward from this line below $1 / C_{\mathrm{S}}{ }^{1 / 2}=c a . \quad 4.5\left(\mathrm{~mol} \mathrm{dm}^{-3}\right)^{-1 / 2}$. The linear relation between $A_{2}$ vs. $1 / C_{\mathrm{S}}$ holds for the $A_{2}{ }^{(40)}$ of TMA-gellan solutions in the low $C_{\mathrm{S}}$ range as shown in Figure 4 . Therefore, the ionic strength dependence of $A_{2}{ }^{(40)}$ for the TMA-gellan in TMACl solutions is similar to that observed for typical linear polyelectrolytes.

The concentration $C_{\mathrm{S} \theta}$, where $A_{2}$ becomes zero, is called the $\theta$-concentration. At that point the macromolecules are in an unperturbed state, i.e., $\beta$ in eq 6 becomes zero, ${ }^{15}$ and 


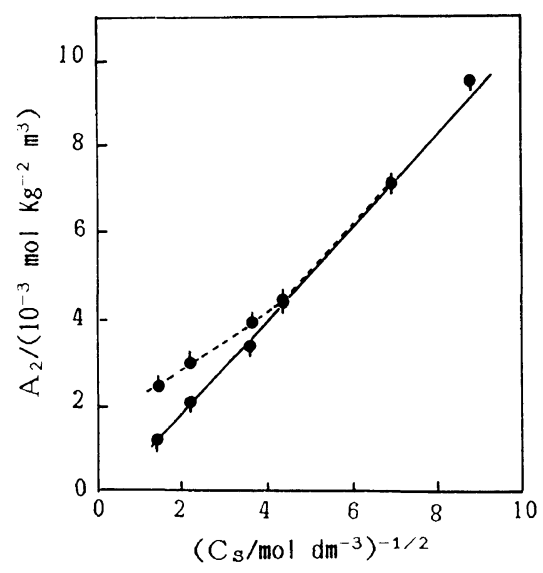

Figure 6. Plots of $A_{2} v s .1 / C_{\mathrm{S}}{ }^{1 / 2}$ for the TMA-gellan in TMACl solutions at $\left.28^{\circ} \mathrm{C}()^{\circ}\right)$ and $40^{\circ} \mathrm{C}\left(\varphi^{\circ}\right.$.

they behave as Gaussian chains. ${ }^{31}$ Here, the $\theta$-point can be determined by extrapolation in the lower range of $1 / C_{\mathrm{S}}{ }^{1 / 2}$. At $40^{\circ} \mathrm{C}, C_{\mathrm{S} \theta}$ becomes $c a$. $16\left(\mathrm{~mol} \mathrm{dm}^{-3}\right)$. However, osmotic pressure measurements for the TMA-gellan at the $\theta$ state were practically impossible due to the gel formation of TMA-gellan solutions with $c=0.5\left(10 \mathrm{~kg} \mathrm{~m}^{-3}\right)$ and $C_{\mathrm{S}}>0.7(\mathrm{~mol}$ $\left.\mathrm{dm}^{-3}\right)$ at $40^{\circ} \mathrm{C}$.

\section{CONCLUSIONS}

Conformational properties of the TMAgellan in aqueous TMACl were studied by osmometry. It was found that the $\left[\bar{M}_{n}\right]^{(28)}$ value was almost twice the value of $\left[\bar{M}_{n}\right]^{(40)}$, which could be interpreted as association of the two molecules at $28^{\circ} \mathrm{C}$ in $\mathrm{TMACl}$ solutions. It was found that the ionic strength dependence of $A_{2}{ }^{(28)}$ for the TMA-gellan in TMACl solutions can be quantitatively described by the theory for the charged long rod model, while that of $\mathrm{A}_{2}{ }^{(40)}$ seems to be similar to the behavior oflinear flexible polyelectrolytes.

Acknowledgments. The author wishes to thank Prof. Kazuyoshi Ogino of Chiba Institute of Technology for his discussions and valuable advice for this study. The author also wishes to thank Dr. Tatsuhiko Tanaka of Science University of Tokyo for the measurements of the contents of metals in the gellan gum samples.

\section{REFERENCES}

1. P. Jansson, B. Linberg, and P. A. Sandford, Carbohydr. Res., 124, 135 (1983).

2. M. A. O'Neill, R. R. Selvendran, and V. J. Morris, Carbohydr. Res., 124, 123 (1983).

3. A. P. Gunning and V. J. Morris, Int. J. Biol. Macromol., 12, 338 (1990).

4. V. Crescezi, M. Dentini, and I. C. M. Dea, Carbohydr. Res., 156, 173 (1986).

5. M. Milas, X. Shi, and M. Rinaudo, Biopolymers, 30, 451 (1990).

6. E. Ogawa, Food Hydrocolloids, 7, 397 (1993).

7. H. Yamakawa, "Modern Theory of Polymer Solutions," Harper \& Row, New York, N. Y., 1971, Chapter 7.

8. W. R. Krigbaum and P. J. Flory, J. Am. Chem. Soc., 75, 1775 (1953).

9. W. H. Stockmayer and E. F. Casassa, J. Chem. Phys., 20, 156 (1952).

10. F. G. Donnan and E. A. Guggenheim, Z. Physik. Chem., 162, 346 (1932).

11. F. G. Donnan, Z. Physik. Chem., 168, 369 (1934).

12. J. T. Edall, H. Edelhoch, R. Lontie, and P. R. Morrison, J. Am. Chem. Soc., 72, 4641 (1950).

13. E. G. Richards, "An Introduction to Physical Properties of Large Molecules in Solution", Cambridge University Press, Cambridge, 1980, Chapter 9.

14. H. Morawertz, "High Polymers XXI, Macromolecules in Solution," Interscience Publishers, New York, London, Sydney, 1965, Chapter 7.

15. M. Nagasawa and A. Takahashi, "Light Scattering from Polymer Solutions," M. B. Huglin, Ed., Academic Press, London \& New York, 1972, Chapter 16.

16. H. Yamakawa, "Modern Theory of Polymer Solutions," Harper \& Row, New York, N. Y., 1971, Chapter 4.

17. T. Nicolai and M. Mandel, Macromolecules, 22, 438 (1989).

18. S. L. Brenner and V. A. Parsegian, Biophys. J., 14, 327 (1974).

19. D. Stigter, Biopolymers, 16, 1435 (1977).

20. M. Fixman and J. Skolnik, Macromolecules, 11, 5, 863 (1978).

21. C. F. Anderson and M. T. Record, Jr., Ann. Rev. Phys. Chem., 33, 191 (1982).

22. G. S. Manning, J. Chem. Phys., 51, 3, 924 (1969).

23. A. Strootbants, H. N. W. Lekkerkerker, and Th. Odijk, Macromolecules, 19, 2232 (1986). 


\section{E. Ogawa}

24. T. Okamoto, K. Kubota, and N. Kuwahara, Food Hydrocolloids, 7, 363 (1993).

25. H. Yamakawa and M. Fujii, Macromolecules, 6, 407 (1973).

26. K. Kawakami and T. Norisuye, Macromolecules, 24, 174898 (1991).

27. A. Takahashi, T. Kato, and M. Nagasawa, J. Phys. Chem., 71, 7, 2001 (1967).
28. A. Takahashi, N. Kato, and M. Nagasawa, J. Phys. Chem., 74, 4, 944 (1970).

29. E. Nordmeier and W. Dauwe, Polym. J., 24, 3, 229 (1992).

30. Z. Alexandrowicz, J. Polym. Sci., A2, 6, 1227 (1968).

31. T. Kitano, A. Taguchi, and I. Noda, Macromolecules, 13, 57 (1980). 